\title{
Magnesium Nanoparticles With Pd Decoration for Hydrogen Storage
}

\author{
Yana Liu ${ }^{1,2}$, Jinglian Zhu ${ }^{1,2}$, Zhibing Liu ${ }^{1,2}$, Yunfeng Zhu ${ }^{1,2 *}$, Jiguang Zhang ${ }^{1,2}$ and \\ Liquan $L i^{1,2}$ \\ ${ }^{1}$ College of Materials Science and Engineering, Nanjing Tech University, Nanjing, China, ${ }^{2}$ Jiangsu Collaborative Innovation \\ Centre for Advanced Inorganic Function Composites, Nanjing Tech University, Nanjing, China
}

In this work, Magnesium nanoparticles with $\mathrm{Pd}$ decoration, ranging from 40 to $70 \mathrm{~nm}$, were successfully coprecipitated from tetrahydrofuran (THF) solution, assigned as the $\mathrm{Mg}-\mathrm{Pd}$ nanocomposite. The Mg-Pd nanocomposite exhibits superior hydrogen storage properties. For the hydrogenated $\mathrm{Mg}-\mathrm{Pd}$ nanocomposite at $150^{\circ} \mathrm{C}$, the onset dehydrogenation temperature is significantly reduced to $216.8^{\circ} \mathrm{C}$, with a lower apparent activation energy for dehydrogenation of $93.8 \mathrm{~kJ} / \mathrm{mol} \mathrm{H}$. High-content $\gamma-\mathrm{MgH}_{2}$ formed during the hydrogenation process, along with $\mathrm{PH}_{0.706}$, contributes to the enhancing of desorption kinetics. The Mg-Pd nanocomposite can take up $3.0 \mathrm{wt} \%$ hydrogen in $2 \mathrm{~h}$ at a temperature as low as $50^{\circ} \mathrm{C}$. During lower hydrogenation temperatures, $\mathrm{Pd}$ can dissociate hydrogen and create a hydrogen diffusion pathway for the $\mathrm{Mg}$ nanoparticles,

OPEN ACCESS

Edited by:

Zhenguo Huang,

University of Technology

Sydney, Australia

Reviewed by:

Xuezhang Xiao,

Zhejiang University, China

Jianfeng Mao,

University of Wollongong, Australia

*Correspondence:

Yunfeng Zhu

yfzhu@njtech.edu.cn

Specialty section:

This article was submitted to

Electrochemistry,

a section of the journal

Frontiers in Chemistry

Received: 18 November 2019 Accepted: 31 December 2019

Published: 19 February 2020

Citation:

Liu Y, Zhu J, Liu Z, Zhu Y, Zhang J and Li L (2020) Magnesium Nanoparticles With Pd Decoration for Hydrogen

Storage. Front. Chem. 7:949. doi: 10.3389/fchem.2019.00949 leading to the decrease of the hydrogenation apparent activation energy $\left(44.3 \mathrm{~kJ} / \mathrm{mol} \mathrm{H}_{2}\right)$. In addition, the Mg-Pd alloy formed during the hydrogenation/dehydrogenation process can play an active role in the reversible metal hydride transformation, destabilizing the $\mathrm{MgH}_{2}$.

Keywords: Mg-based nanoparticles, coprecipitation, hydrogen storage, $\gamma-\mathrm{MgH}_{2}$ phase, $\mathrm{Pd}$ decoration

\section{INTRODUCTION}

Magnesium hydride has been favorable to be applied foreground in onboard hydrogen storage systems, due to its high gravimetric hydrogen storage capacity (7.6 wt\%), natural abundance, and good reversibility. Unfortunately, pure $\mathrm{MgH}_{2}$ shows slow sorption kinetics and high thermodynamic stability regarding the covered surface oxide layer and the low diffusion coefficient for $\mathrm{H}$ (Pistidda et al., 2014; Crivello et al., 2016; Yartys et al., 2019). In order to overcome these drawbacks of $\mathrm{MgH}_{2}$ for practical applications, numerous studies attempted to enhance the hydrogen storage performance of $\mathrm{MgH}_{2}$, such by as alloying $\mathrm{Mg}$ with other elements to alter the thermodynamic stability, doping with additives or catalysts, and reducing $\mathrm{Mg}$ particles to nano scale. "Nanosize effect" has been considered as an approach with the potential of leading to improvements in both kinetics and thermodynamics (Schneemann et al., 2018), which is based on (i) a larger surface area and thus more hydrogen dissociation sites (ii) the shortened hydrogen diffusion distances which in turn enhance kinetics, and (iii) the increased number of atoms at grain boundaries to enhance the hydrogen diffusion rates (Yao et al., 2011; Schneemann et al., 2018; Sun et al., 2018). Recently, an adapted Rieke method has emerged as an alternative to synthesize $\mathrm{Mg}$ nanoparticles to dramatically enhance the hydrogen sorption kinetics of $\mathrm{Mg}$. For instance, Jeon et al. (2011) reported the synthesis of air-stable Mg nanoparticles $(\sim 4.9 \mathrm{~nm})$ embedded in PMMA matrix, which enable both the storage of a high hydrogen capacity and rapid kinetics. 
Norberg et al. (2011) prepared Mg nanoparticles with controllable sizes by a similar method, and the ab-/desorption hydrogen kinetics were proven to be dramatically faster for nanoparticles with smaller sizes, as a result of the increase of the defect density formed in smaller nanoparticles. Recently, we have investigated that the Mg-TM $(\mathrm{TM}=\mathrm{Ni}, \mathrm{Ti}, \mathrm{Fe}, \mathrm{Co}$, and $\mathrm{V}$ ) nanocomposites can be coprecipitated from solution, in which the coprecipitated $\mathrm{Ni}, \mathrm{Ti}, \mathrm{Fe}, \mathrm{V}$, or Co has high catalytic efficiency in improvement of the ab-/desorption hydrogen kinetics of Mg nanoparticles (Liu et al., 2014a,b, 2015). The adapted Rieke method is considered as a better method for the preparation of nano-sized $\mathrm{Mg}$ with controllable sizes, and which can dope transition metal catalysts into a $\mathrm{Mg} / \mathrm{MgH}_{2}$ system by a simple chemical route. With regard to the nanoscaling, various catalysts for improving the hydrogen storage properties of $\mathrm{MgH}_{2}$ have been investigated, such as transition metals/metal oxides/halogenides (Ma et al., 2009, 2013; Cui et al., 2014; Rizo-Acosta et al., 2018; Zhang et al., 2018; Liu et al., 2019b), rare earth metal oxides/halogenides (Singh et al., 2013; Lin et al., 2014, 2015; Wang et al., 2015), carbon materials (Lukashev et al., 2006; Liu et al., 2013; Rather et al., 2016), and other hydrides (Lu et al., 2010; Terent'ev et al., 2015; Jangir et al., 2018). In addition, some noble metals, such as $\mathrm{Pd}$, have been reported to be effective for facilitating hydrogenation of $\mathrm{MgH}_{2}$ (Du et al., 2007; Callini et al., 2010; Ham et al., 2013; Chung et al., 2015; Liu et al., 2019a). Liu et al. (2019a) reported that elemental Pd played a dominant role in accelerating the preferential diffusion of hydrogen atoms at the $\mathrm{Pd} / \mathrm{Mg}$ interface, during the hydrogenation process. Callini et al. (2009) suggested the occurrence of Mg-alloying as a path for subsequent feasible $\mathrm{H}$-exchange, when $\mathrm{Pd}$ was deposited on top of a thick MgO layer surrounding the Mg NPs core. Du et al. (2007) reported that the Pd-dopant provides a much lower activation barrier for both dissociation of molecular hydrogen and diffusion of atomic hydrogen on the $\mathrm{Mg}$ surface, based on $\mathrm{ab}$ initio density functional theory calculations.

Inspired by the above considerations, a $\mathrm{Mg}-\mathrm{Pd}$ nanocomposite was coprecipitated from THF solution. The $\mathrm{Mg}$ nanoparticles were homogeneously decorated with nanosized Pd. The hydrogen sorption properties were investigated, and the catalytic mechanisms of Pd were also proposed.

\section{MATERIALS AND METHODS}

\section{Sample Preparation}

As early as in 1972, Rieke et al. reported a general procedure for the preparation of highly reactive magnesium metal, which was prepared by reducing a magnesium halide with alkali metal in an ethereal solvent (Rieke and Hudnall, 1972). In this work, anhydrous $\mathrm{MgCl}_{2}, \mathrm{PdCl}_{2}$, lithium naphthalide (LiNp), and tetrahydrofuran (THF) solution were introduced to prepare the $\mathrm{Mg}-\mathrm{Pd}$ nanocomposite by the coprecipitation method (an adapted Rieke method). During the sample preparation process, the real reducing agent is metal $\mathrm{Li}$, while naphthalene is used as an electron carrier. Due to the presence of naphthalene, metal Li would dissolve in THF, forming a blackish green solution, which can speed up the reduction reaction of active $\mathrm{Mg}$. In raw materials, $\mathrm{Pd}: \mathrm{Mg}$ was kept in a weight ratio of 1:9. The reaction processes are as follows:

$$
\begin{aligned}
\mathrm{MgCl}_{2}+2 \mathrm{Li} & \rightarrow \mathrm{Mg}^{*}+2 \mathrm{LiCl} \\
\mathrm{PdCl}_{2}+2 \mathrm{Li} & \rightarrow \mathrm{Pd}^{*}+2 \mathrm{LiCl}
\end{aligned}
$$

Naphthalene $(5.52 \mathrm{~g})$ and lithium $(0.299 \mathrm{~g})$ were dissolved in the freshly distilled THF $(50 \mathrm{ml})$, forming a homogeneous blackish green solution (LiNp/THF). A mixed THF solution of $\mathrm{MgCl}_{2}$ and $\mathrm{PdCl}_{2}$ was prepared by anhydrous $\mathrm{MgCl}_{2}(1.904 \mathrm{~g})$ and $\mathrm{PdCl}_{2}$ $(0.09 \mathrm{~g})$ dissolved in $200 \mathrm{ml} \mathrm{THF}$ at $60-70^{\circ} \mathrm{C}$. The coprecipitation reaction process and the separation and drying process of nanocomposites were performed with reference to a relevant literature report (Liu et al., 2014b).

\section{Sample Characterization}

The crystal structure and the phase composition of the samples were analyzed by X-ray diffraction (XRD) with $\mathrm{Cu} \mathrm{K} \alpha$ radiation $(40 \mathrm{kV}$ and $35 \mathrm{~mA})$ using an ARL X'TRA diffractometer. The morphology and microstructure of as-prepared samples were observed by using a JEM-2100F transmission electron microscope (TEM). A Sieverts-type apparatus (AMC) was used to examine the hydrogen storage properties. The auto pressure-composition-temperature (PCT) measurements were performed under a hydrogen pressure up to $4 \mathrm{MPa}$. The hydrogen absorption kinetics was characterized under an initial hydrogen pressure of 3.0 MPa. The dehydrogenation experiments were performed using diffraction scanning calorimetry (DSC, Netzsch STA 449F3) at various heating rates under Ar gas flow.

\section{RESULTS AND DISCUSSION}

\section{Microstructural Characterization}

Figure 1 presents the XRD patterns of the $\mathrm{Mg}-\mathrm{Pd}$ nanocomposite in varying states. As shown in Figure 1A,

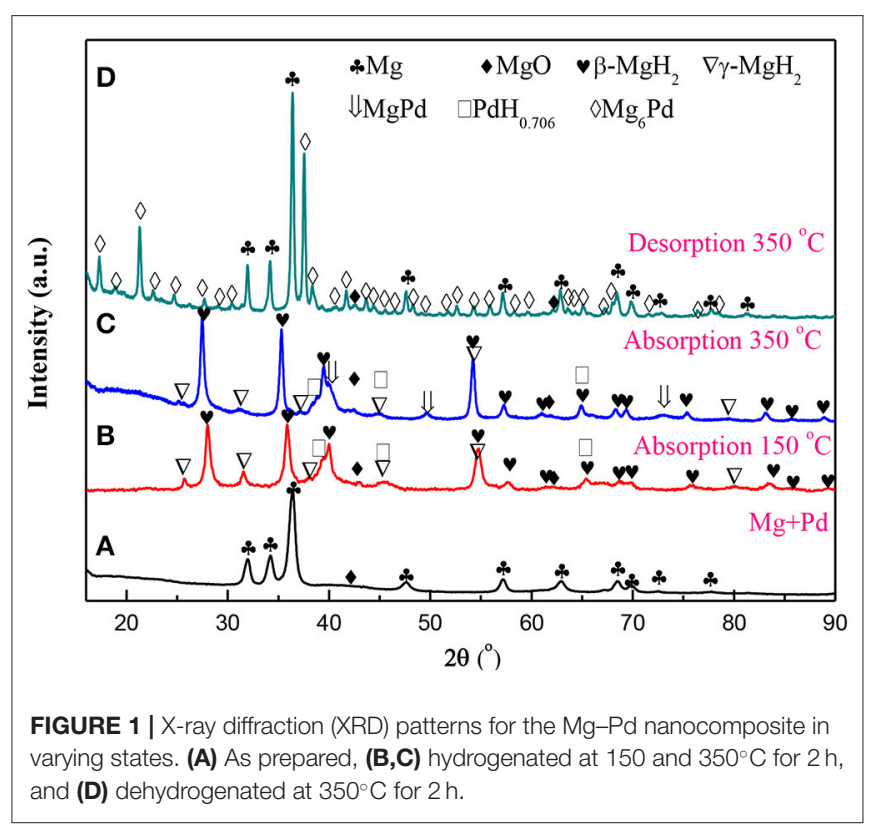


almost all diffraction peaks of as-prepared nanocomposite can be characterized with the hexagonal $\mathrm{Mg}$ phase. Only a weak peak at $\sim 42.9^{\circ}$ can be indexed with $\mathrm{MgO}$, and the characteristic diffraction peaks of $\mathrm{Pd}$ are absent. A small amount of $\mathrm{MgO}$ is likely due to the oxidation in the process of sample preparation for the XRD analysis, as a result of high chemical activity of Rieked Mg. The absence of Pd peaks suggests that $\mathrm{Pd}$ synthetized from solution is in the form of extremely fine particles or amorphous, and hence, it does not generate detectable diffraction intensity. A similar phenomenon has been found in our previous research work (Liu et al., 2014a, 2015). The lattice parameters of the $\mathrm{Mg}$ phase can be refined to be $\mathrm{a}=\mathrm{b}=0.3225 \mathrm{~nm}$, and $\mathrm{c}=0.5242 \mathrm{~nm}$ for the $\mathrm{Mg}-\mathrm{Pd}$ nanocomposite, which are slightly larger than those of pure $\mathrm{Mg}$ reduced by the same method $(\mathrm{a}=\mathrm{b}=0.3196 \mathrm{~nm}, \mathrm{c}=0.5199 \mathrm{~nm}$; Liu et al., 2014b), indicating that a part of the Pd atoms may get into the crystal lattice of the $\mathrm{Mg}$ during the preparation, resulting in the lattice expansion of $\mathrm{Mg}$. In addition, the average crystallite of $\mathrm{Mg}$ can be determined to be about $22.5 \mathrm{~nm}$ by the Scherrer equation. When the $\mathrm{Mg}-\mathrm{Pd}$ nanocomposite was hydrogenated under $3 \mathrm{MPa}$ hydrogen pressure at $150^{\circ} \mathrm{C}$ for $2 \mathrm{~h}$, the majority phases of the hydrogenated $\mathrm{Mg}-\mathrm{Pd}$ nanocomposite are the tetragonal $\beta-\mathrm{MgH}_{2}$ and the orthogonal $\gamma-\mathrm{MgH}_{2}$, along with a small amount of $\mathrm{MgO}$ and $\mathrm{PdH}_{0.706}$ phases, as shown in Figure 1B. The metastable $\gamma-\mathrm{MgH}_{2}$, belonging to a- $\mathrm{PbO}_{2}$-type orthorhombic crystal structure, is usually produced by ball milling (Varin et al., 2006; Ponthieu et al., 2013; Zhou et al., 2015) as well as under high compressive stress (Vajeeston et al., 2006; Siviero et al., 2009; Ham et al., 2013). Zhou et al. (2013) pointed out that the $\mathrm{H}$ octahedrons surrounding $\mathrm{Mg}$ atoms are deformed in the $\gamma-\mathrm{MgH}_{2}$. Besides, the octahedral chain takes a zigzag form, while for the $\beta-\mathrm{MgH}_{2}$, the chain is straight. Sander et al. studied hydrogen transport kinetics in $\beta$ - (termed $\alpha-\mathrm{MgH}_{2}$ in their study) and $\gamma-\mathrm{MgH}_{2}$ based on theoretical calculations and found that $\mathrm{H}$ vacancies' concentrations are higher and more mobile in the $\gamma-\mathrm{MgH}_{2}$ than in the $\beta-\mathrm{MgH}_{2}$ (Sander et al., 2016). Therefore, we can speculate that the metastable $\gamma-\mathrm{MgH}_{2}$ structure is likely due to the deformations and structural defects formed in the $\mathrm{MgH}_{2}$ lattice during the preparation (ball milling or under high compressive stress). The formation of the $\gamma-\mathrm{MgH}_{2}$ phase is also found in the $\mathrm{Mg}-\mathrm{TM}(\mathrm{TM}=\mathrm{Ni}, \mathrm{Ti}, \mathrm{Fe}, \mathrm{Co}$, and $\mathrm{V})$ nanocomposites coprecipitated from solution (Liu et al., 2014a,b, 2015). Norberg et al. (2011) proposed that a high density of defects may form in the $\mathrm{Mg}$ lattice through the adapted Rieked method. In addition, Xiao et al. (2016) synthesized $\beta-/ \gamma-\mathrm{MgH}_{2}$ nanocomposites via a simple wet chemical route by ball milling $\mathrm{MgH}_{2}$ with $\mathrm{LiCl}$ as an additive at room temperature followed by THF treatment and revealed that THF solution plays a vital role in the synthesis of the $\gamma-\mathrm{MgH}_{2}$ phase. In this work, high-density defects formed in the nanocomposite and THF solution effect may contribute to the formation of the $\gamma-\mathrm{MgH}_{2}$ phase at lower temperature. On hydrogen loading, the $\mathrm{PdH}_{0.706}$ peaked at $38.7^{\circ} \mathrm{C}$, corresponding to the (111) plane. The $\mathrm{PdH}_{0.706}$ phase also could be found when $\mathrm{Au} / \mathrm{Mg} / \mathrm{Pd}$ films were hydrogenated at $200^{\circ} \mathrm{C}$ (Akyildiz et al., 2006). As the temperature was increased to $350^{\circ} \mathrm{C}$, in addition to the main phase of $\beta-\mathrm{MgH}_{2}, \mathrm{MgPd}, \mathrm{PdH} 0.706$, and $\gamma-\mathrm{MgH}_{2}$ phases were clearly detected in Figure 1C. The appearance of the Pd-richer intermetallic compound $\mathrm{MgPd}$ indicates that $\mathrm{Pd}$ is inter-mixing with $\mathrm{Mg}$ at the $\mathrm{Pd}-\mathrm{Mg}$ interface, which is considered to be the equilibrium end product (Callini et al., 2010). The amount of $\gamma-\mathrm{MgH}_{2}$ phase in hydrogenated nanocomposite decreased with increasing the hydrogenation temperature, due to the removal of the lattice deformation and structural defects in $\mathrm{Mg}$ at high temperature. Shena and Aguey-Zinsou, reported that the $\gamma-\mathrm{MgH}_{2}$ was fully converted to $\beta-\mathrm{MgH}_{2}$ after hydrogen cycling at $200^{\circ} \mathrm{C}$, due to the annealing of defects and relief of strain (Shena and Aguey-Zinsou, 2017). After dehydrogenation at $350^{\circ} \mathrm{C}$ for $2 \mathrm{~h}$ under $0.05 \mathrm{MPa}$ hydrogen pressure, the phases of $\mathrm{Mg}, \mathrm{MgO}$, and $\mathrm{Mg}_{6} \mathrm{Pd}$ could be detected in the XRD pattern of Figure 1D. The formation of $\mathrm{Mg}_{6} \mathrm{Pd}$ confirms an interaction between $\mathrm{MgH}_{2}$ and $\mathrm{MgPd}$ or $\mathrm{PdH}_{0.706}$ during the process of dehydrogenation, as in following equations:

$$
\begin{aligned}
\mathrm{MgPd}+5 \mathrm{MgH}_{2} & \rightarrow \mathrm{Mg}_{6} \mathrm{Pd}+5 \mathrm{H}_{2} \\
\mathrm{PdH}_{0.706}+6 \mathrm{MgH}_{2} & \rightarrow \mathrm{Mg}_{6} \mathrm{Pd}+7.412 \mathrm{H}_{2}
\end{aligned}
$$

Huot et al. (2009) found that the bulk $\mathrm{Mg}_{6} \mathrm{Pd}$ could reversibly absorb hydrogen in three disproportionation reactions and finally be transformed to the $\mathrm{MgPd}$ phase again. $\mathrm{MgPd}$ or $\mathrm{Pd}_{\mathrm{H} 0.706}$ interacting with $\mathrm{MgH}_{2}$ may alter the thermodynamics of the dehydrogenation of $\mathrm{MgH}_{2}$. Therefore, the thermodynamics of the $\mathrm{Mg}-\mathrm{Pd}$ nanocomposite will be discussed in greater detail later.

STEM micrographs and SAED pattern of the $\mathrm{Mg}-$ $\mathrm{Pd}$ nanocomposite are shown in Figure 2. The $\mathrm{Mg}-\mathrm{Pd}$ nanocomposite is composed of irregularly shaped particles aggregating together, with their particle sizes ranging from 40
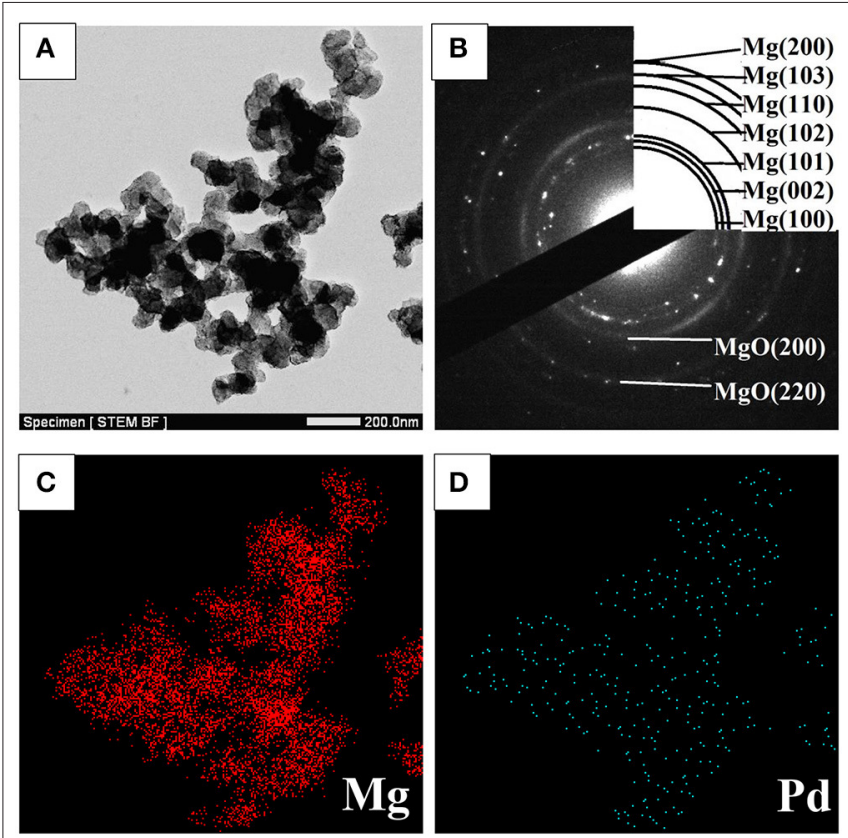

FIGURE 2 | (A) STEM micrograph and (B) SAED pattern of the Mg-Pd nanocomposite, along with (C,D) EDS elemental maps of $\mathrm{Mg}$ and Pd. 
to $70 \mathrm{~nm}$, as shown in Figure 2A, while for the pure $\mathrm{Mg}$ without doping catalysts, the nanoparticles were plate-shaped and stacked together forming a shape like a "chicken claws" structure (Liu et al., 2014b). The above result indicates that doping with $\mathrm{Pd}$ may dramatically affect the preferred orientation of $\mathrm{Mg}$ particle growth. As shown in the corresponding SAED pattern (Figure 2B), the diffraction rings or points can be indexed with $\mathrm{Mg}$ and $\mathrm{MgO}$ phase, without $\mathrm{Pd}$, which is in accordance with the XRD result. In order to qualitatively evaluate the distribution of $\mathrm{Pd}$ in $\mathrm{Mg}$ particles, EDS elemental maps of $\mathrm{Mg}$ and $\mathrm{Pd}$ were performed. As can be seen, Pd is homogeneously distributed on the surface or inside Mg particles, without obvious reunion phenomenon. The actual $\mathrm{Pd}$ weight content in the nanocomposite is about $5 \mathrm{wt} \%$, much lower than the initial doping amount. Only half the amount of Pd was embedded in or attached on the surface of $\mathrm{Mg}$ particles, and the rest might be lost during the centrifugation and repeated washing processes. The TEM micrograph and the corresponding SAED pattern of the $\mathrm{Mg}-\mathrm{Pd}$ nanocomposite hydrogenated at $150^{\circ} \mathrm{C}$ for $2 \mathrm{~h}$ are shown in Figures 3A,B, respectively. As can be seen, the particle size of the hydrogenated $\mathrm{Mg}-\mathrm{Pd}$ nanocomposite ranges from 20 to $30 \mathrm{~nm}$, much lower than that hydrogenated before, which is likely due to a large number of nucleation sites at the Mg-Pd interface and high density of defects on the $\mathrm{Mg}$ particles. The same phenomenon was found in the previously reported $\mathrm{Mg}-\mathrm{TM}(\mathrm{TM}=\mathrm{Ni}, \mathrm{Ti}, \mathrm{Fe}, \mathrm{Co}$, and $\mathrm{V})$ nanocomposites (Liu et al., 2014a,b, 2015). As shown in the STEM images, Pd is homogeneously distributed on the surface or inside Mg particles, without obvious reunion phenomenon. Kumar et al. has reported that multinucleation sites for the $\mathrm{Mg} \rightarrow \mathrm{MgH}_{2}$ hydrogenation process could be created by the uniformly distributed catalyst on the $\mathrm{Mg}$ nanoparticle surface, which could prevent grain growth (Kumar et al., 2017). A high density of defects on the Mg particles could also be found in the previously reported $\mathrm{Mg}-\mathrm{TM}(\mathrm{TM}=\mathrm{Ni}, \mathrm{Ti}, \mathrm{Fe}, \mathrm{Co}$, and $\mathrm{V})$ nanocomposites (Liu et al., 2014a,b, 2015) and Mg nanocrystals prepared by Norberg et al. (2011), which could provide more nucleation sites for the $\mathrm{Mg} \rightarrow \mathrm{MgH}_{2}$ hydrogenation process. In addition, the particles' growth trend is not obvious at lower hydrogenation temperature $\left(150^{\circ} \mathrm{C}\right)$, resulting in the refinement of $\mathrm{MgH}_{2}$ particles. As shown in Figure 3B, no diffraction

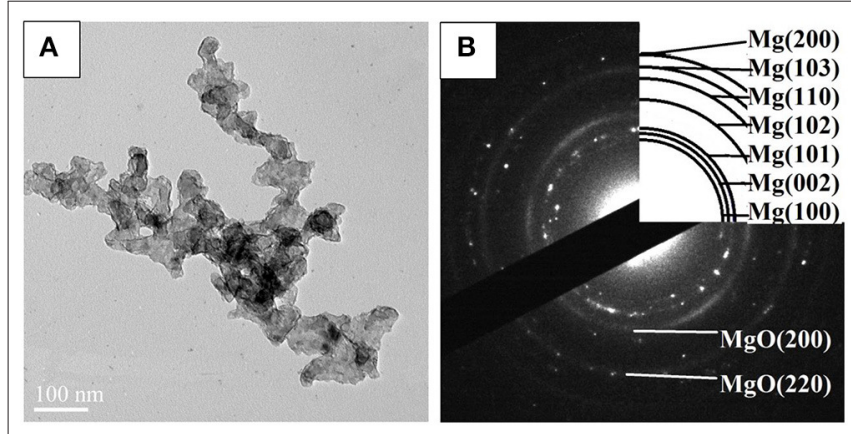

FIGURE 3 | (A) Transmission electron microscope (TEM) micrograph and (B) SAED pattern of the $\mathrm{Mg}-\mathrm{Pd}$ nanocomposite hydrogenated at $150^{\circ} \mathrm{C}$ for $10 \mathrm{~h}$. rings or points can be indexed with the $\beta-/ \gamma-\mathrm{MgH}_{2}$ phase, suggesting that the electron beam induces full dehydrogenation of $\mathrm{MgH}_{2}$ during the TEM measurement under high-vacuum conditions. Besides, $\mathrm{Pd}$ or $\mathrm{PdH}_{0.706}$ is not found, maybe due to the poor crystallinity.

\section{The Effects of $\mathrm{Mg}_{6} \mathrm{Pd}$ on the Thermodynamics}

Figure 4A displays the PCT curves of the $\mathrm{Mg}-\mathrm{Pd}$ nanocomposite measured at different temperatures in a hydrogen pressure range from 0.02 to $4 \mathrm{MPa}$. The first hydrogen cycle at $350^{\circ} \mathrm{C}$ was conducted for the test sample to obtain a $\mathrm{Mg}-\mathrm{Mg}_{6} \mathrm{Pd}$ system. It can be found that only one plateau is present across the whole range of the hydrogen content in each PCT curve. Obvious plateaus of $\mathrm{Mg}_{6} \mathrm{Pd}$ cannot be clearly identified. However, previous investigation (Huot et al., 2009) showed that the hydrogen absorption process of $\mathrm{Mg}_{6} \mathrm{Pd}$ was divided into three stages:

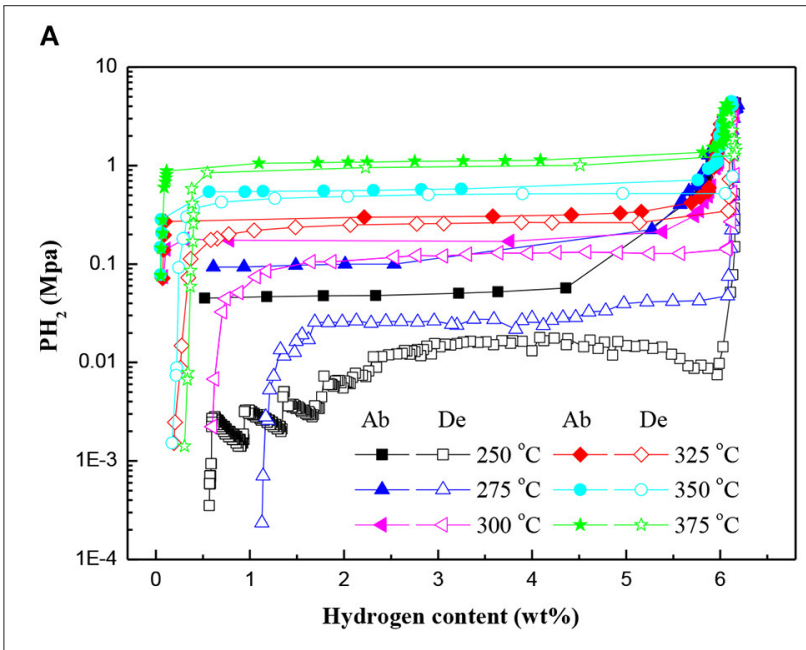

B

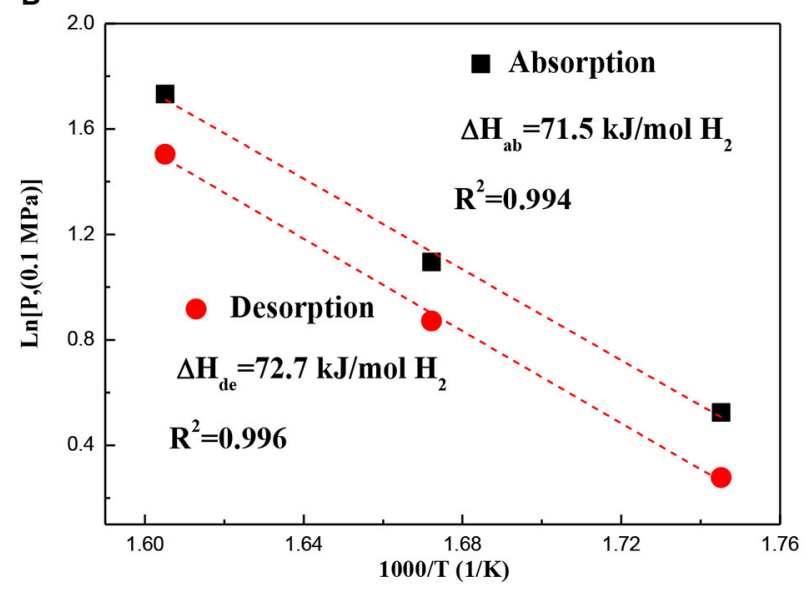

FIGURE 4 | (A) PCT curves of the Mg-Pd nanocomposite measured at different temperatures and (B) the corresponding van't Hoff plots. Ab, absorption; De, desorption. 


$$
\begin{aligned}
\mathrm{Mg}_{6} \mathrm{Pd} & +2.35 \mathrm{H}_{2} \leftrightarrow 2.35 \mathrm{MgH}_{2}+\mathrm{Mg}_{3.65} \mathrm{Pd} \\
2.35 \mathrm{MgH}_{2} & +\mathrm{Mg}_{3.65} \mathrm{Pd}+1.15 \mathrm{H}_{2} \leftrightarrow 3.5 \mathrm{MgH}_{2} \\
& +0.5 \mathrm{Mg}_{2} \mathrm{Pd}_{5} \\
3.5 \mathrm{MgH}_{2} & +0.5 \mathrm{Mg}_{2} \mathrm{Pd}_{5}+1.15 \mathrm{H}_{2} \leftrightarrow \mathrm{MgPd}+5 \mathrm{MgH}_{2}
\end{aligned}
$$

A higher plateau should appear in the PCT curve, which is attributed to the transformation $\mathrm{Mg}_{6} \mathrm{Pd}+5 \mathrm{H}_{2} \leftrightarrow$ $\mathrm{MgPd}+5 \mathrm{MgH}_{2}$. In addition, Shena and Aguey-Zinsou (2017) reported that $\mathrm{P}\left(\mathrm{H}_{2}\right)_{\mathrm{abs}}=5 \mathrm{MPa}$ is not sufficient to induce the formation of MgPd at the higher temperature of $350^{\circ} \mathrm{C}$. In fact, at $350^{\circ} \mathrm{C}, 3 \mathrm{MPa}$ is enough for the formation of $\mathrm{MgPd}$, as shown in Figure 1C. This is in accordance with the one plateau observed in the PCT curve for the $\mathrm{Mg}-\mathrm{Mg}_{6} \mathrm{Pd}$ system, suggesting an excellent synergistic effect for $\mathrm{Mg}$ and $\mathrm{Mg}_{6} \mathrm{Pd}$ during hydrogenation/dehydrogenation processes. The corresponding van't Hoff plot (ln P vs. $1 / \mathrm{T}$ ) is used to estimate hydrogenation and dehydrogenation enthalpies, as shown in Figure 4B. The hydrogenation and dehydrogenation enthalpies are determined to be -71.5 and $72.7 \mathrm{~kJ} \mathrm{~mol}^{-1} \mathrm{H}_{2}$, respectively, which are slightly lower than that of pristine $\mathrm{MgH}_{2}(74.7 \mathrm{~kJ}$ mol- ${ }^{1} \mathrm{H}_{2}$; Crivello et al., 2016). Zhang et al. found that $\mathrm{MgH}_{2}$ is preferentially decomposed by virtue of the Mg-Pd alloy instead of self-decomposition, which can reduce thermal stability of the $\mathrm{MgH}_{2}$ through interacting with $\mathrm{MgH}_{2}$ and forming the $\mathrm{Mg}_{6} \mathrm{Pd}$ phase (Zhang et al., 2015). Therefore, it is reasonable to suggest that the $\mathrm{Mg}-\mathrm{Pd}$ alloy plays an active role in the reversible metal hydride transformation, destabilizing the $\mathrm{MgH}_{2}$.

\section{The Effects of $\gamma-\mathrm{MgH}_{2}$ and $\mathrm{PdH}_{0.706}$ on Dehydrogenation Performances}

DSC curves and the corresponding $\ln \left(\beta / T_{p}{ }^{2}\right)-1,000 / T_{p}$ plots for the hydrogenated $\mathrm{Mg}-\mathrm{Pd}$ nanocomposite are shown in Figure 5. The $\mathrm{Mg}-\mathrm{Pd}$ nanocomposite was hydrogenated at $150^{\circ} \mathrm{C}$ for $2 \mathrm{~h}$, as the test sample. Figure 5A shows that there is a broader and asymmetrical endothermic peak corresponding to desorption of the $\gamma-\mathrm{MgH}_{2}$ and $\beta-\mathrm{MgH}_{2}$ phases in 238.5 and $248.9^{\circ} \mathrm{C}$ at heating rates of 3 and $5^{\circ} \mathrm{C} / \mathrm{min}$, respectively, while for the heating rates of $10^{\circ} \mathrm{C} / \mathrm{min}$, the final endothermic peak is a superposition of two contributing peaks of 265.3 and $281.8^{\circ} \mathrm{C}$. The above results suggest that $\gamma-\mathrm{MgH}_{2}$ decomposes along with the $\beta$ $\mathrm{MgH}_{2}$, which may trigger the decomposition of the $\beta-\mathrm{MgH}_{2}$ during the dehydrogenation process. The onset dehydrogenation temperature at a heating rate of $3^{\circ} \mathrm{C} / \mathrm{min}$ is reduced to $216.8^{\circ} \mathrm{C}$, representing a $94.3^{\circ} \mathrm{C}$ reduction as compared with the pure $\mathrm{MgH}_{2}$ prepared through the same method (Liu et al., 2014b), and for the reported $\mathrm{Mg}-\mathrm{TM}(\mathrm{TM}=\mathrm{Ni}, \mathrm{Ti}, \mathrm{Fe}, \mathrm{Co}$, and V) nanocomposites, the onset dehydrogenation temperatures were determined to be $244.6,296.1,246.5,249.1$, and $278.2^{\circ} \mathrm{C}$, respectively (Liu et al., 2014a,b, 2015). The hydrogenated Mg-Pd nanocomposite exhibits superior hydrogen desorption kinetics compared with the previously reported $\mathrm{Mg}-\mathrm{TM}(\mathrm{TM}=\mathrm{Ni}$, $\mathrm{Ti}, \mathrm{Fe}, \mathrm{Co}$, and V) nanocomposites. The pure $\mathrm{MgH}_{2}$ is a single phase of $\beta-\mathrm{MgH}_{2}$, without doping catalyst. The $\gamma$ $\mathrm{MgH}_{2}$ phase is known to be less stable than the $\beta-\mathrm{MgH}_{2}$ phase. The plane (110) of $\gamma-\mathrm{MgH}_{2}$ has a predicted enthalpy of $44.66 \mathrm{~kJ} \mathrm{~mol}-1 \mathrm{H}_{2}$, while for the same $\beta-\mathrm{MgH}_{2}$ plane, the enthalpy is $78.16 \mathrm{~kJ} \mathrm{~mol}^{-1} \mathrm{H}_{2}$ (Zhou et al., 2015). In addition, the heavily distorted $\mathrm{MgH}_{6}$ octahedron in the $\gamma$ $\mathrm{MgH}_{2}$ potentially can facilitate hydrogen diffusion (Sander et al., 2016). Shena and Aguey-Zinsou (2017) proposed that $\gamma-\mathrm{MgH}_{2}$ can further facilitate hydrogen desorption from $\beta$ $\mathrm{MgH}_{2}$, which can act as a pathway for faster hydrogen diffusion. In this work, a higher content of $\gamma-\mathrm{MgH}_{2}$ is achieved in the hydrogenated products, as shown in Figure 1B. Therefore, it can be concluded that the $\gamma-\mathrm{MgH}_{2}$ phase can significantly reduce the dehydrogenation temperature and improve the dehydrogenation kinetics by acting as a pathway for faster hydrogen diffusion. The $\mathrm{PdH}_{0.706}$ phase in the hydrogenated products also is reported to be effective for improving desorption hydrogen kinetics and reducing the hydrogen desorption temperature, which may help the recombination process of $\mathrm{H}$ atoms into hydrogen molecules on the surface (Tang et al., 2008). Higuchi et al. (2002) reported that "cooperative phenomena"
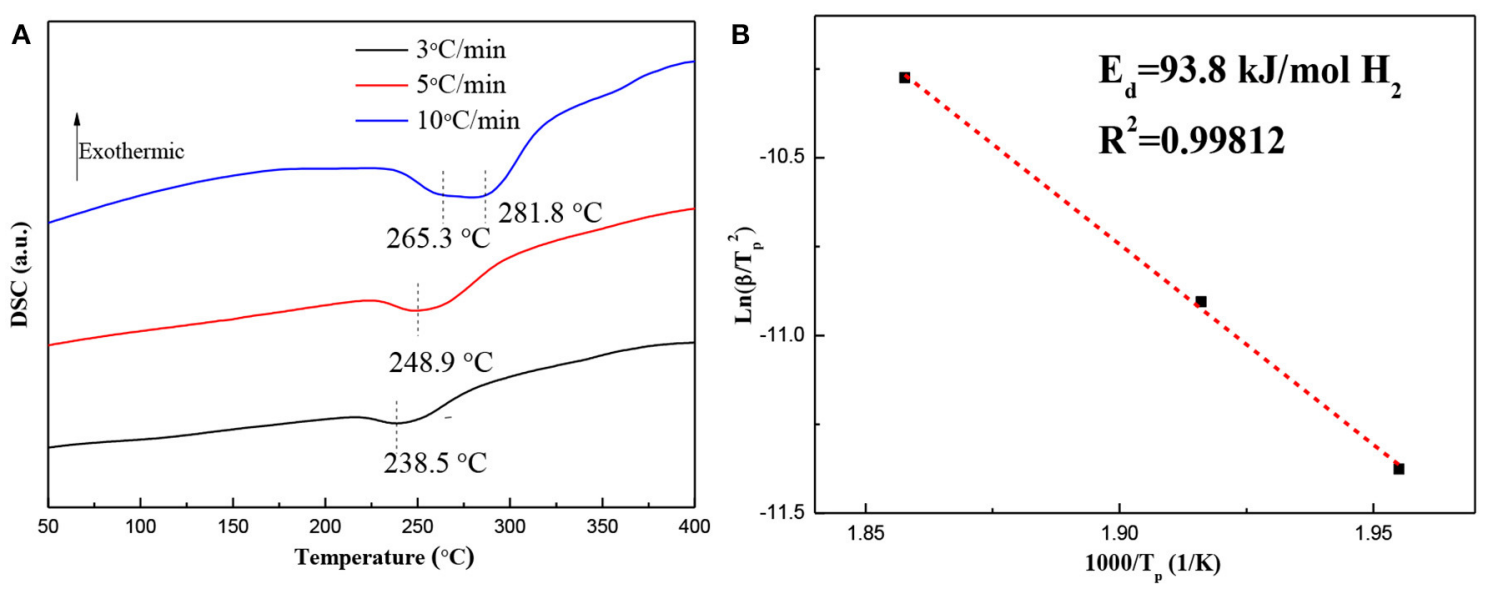

FIGURE 5 | (A) Diffraction scanning calorimetry (DSC) curves and (B) the corresponding $\ln \left(\beta / T_{p}^{2}\right)-1,000 / T_{p}$ plots for the hydrogenated Mg-Pd nanocomposite at different heating rates. 

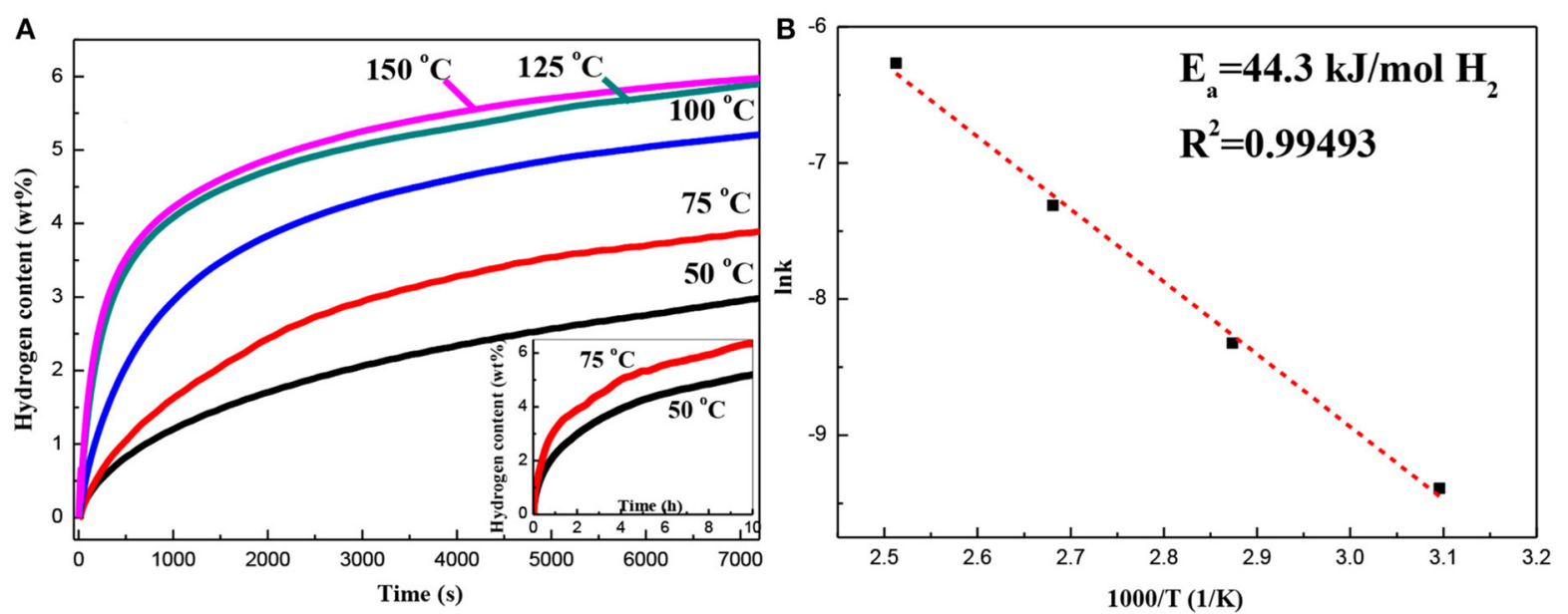

FIGURE 6 | (A) Hydrogen absorption curves of the Mg-Pd nanocomposite measured at different temperatures for $2 \mathrm{~h}$ and (B) the corresponding Ink $-1,000 / T$ plot.

can explain the significant improvement in the dehydriding properties of the $\mathrm{Pd} / \mathrm{Mg} / \mathrm{Pd}$ films, in which hydrogen exhibits elastic interactions between $\mathrm{MgH}_{2}$ and $\mathrm{PdH}_{0.6}$. The activation energy, $E_{d}$, for the hydrogen desorption mechanism of the hydrogenated $\mathrm{Mg}-\mathrm{Pd}$ nanocomposites is estimated by the Kissinger equation:

$$
\ln \left(\beta / T_{p}^{2}\right)=\mathrm{A}-E_{d} /\left(\mathrm{R} T_{p}\right)
$$

where $\beta$ is the heating rate, $T_{p}$ is the peak temperature, and $\mathrm{A}$ is a linear constant.

Figure 5B shows the plot of $\ln \left(\beta / T_{p}^{2}\right)$ vs. $1,000 / T_{p}$ for the hydrogenated $\mathrm{Mg}-\mathrm{Pd}$ nanocomposites. The $E_{d}$ value can be determined to be $93.8 \mathrm{~kJ} / \mathrm{mol} \mathrm{H} \mathrm{H}_{2}$, which is much lower than that of the hydrogenated pure $\mathrm{Mg}(147.4 \mathrm{~kJ} / \mathrm{mol}$ $\mathrm{H}_{2}$; Liu et al., 2014b) and the reported Mg-TM (TM $=\mathrm{Ni}, \mathrm{Ti}, \mathrm{Fe}, \mathrm{Co}$, and $\mathrm{V}$ ) nanocomposites (139.1, 170.9, $118.1,110.1$, and $147.7 \mathrm{~kJ} / \mathrm{mol} \mathrm{H}_{2}$, respectively; Liu et al., 2014a,b, 2015). The lower dehydrogenation temperature and $E_{d}$ value indicate that $\gamma-\mathrm{MgH}_{2}$ and $\mathrm{PH}_{0.706}$ phases formed during the hydrogenation process contribute to the enhancing desorption kinetics.

\section{The Effects of Pd on Lower Temperature Hydrogenation Performances}

Figure 6A shows the first isothermal hydrogen absorption curves of the $\mathrm{Mg}-\mathrm{Pd}$ nanocomposite measured at 50, 75, 100, 125, and $150^{\circ} \mathrm{C}$. As can be seen, the $\mathrm{Mg}-\mathrm{Pd}$ nanocomposite exhibits excellent hydrogen absorption performance. The hydrogen storage capacity can reach up to $3.0 \mathrm{wt} \%$ in $2 \mathrm{~h}$ at $50^{\circ} \mathrm{C}$. In contrast, the hydrogen capacity of the pure $\mathrm{Mg}$ is 2.6 wt $\%$ within $2 \mathrm{~h}$ at a higher temperature of $125^{\circ} \mathrm{C}$. The result suggests that $\mathrm{Pd}$ exhibits high catalytic activity on accelerating the hydrogenation rate of $\mathrm{Mg}$. The apparent activation energy of dehydrogenation can be calculated based on the JohnsonMehl-Avrami-Kolmogorov (JMAK) model and the Arrhenius theory (Liu et al., 2014a,b, 2015). The Arrhenius-type plot of $\ln k$ vs. $1,000 / T$ is drawn in Figure 6B. Thus, $E_{a}$ of the $\mathrm{Mg}-\mathrm{Pd}$ nanocomposite can be determined to be $44.3 \mathrm{~kJ} / \mathrm{mol}$ $\mathrm{H}_{2}$, much lower than that of the pure $\mathrm{Mg}\left(73.1 \mathrm{~kJ} / \mathrm{mol} \mathrm{H} \mathrm{H}_{2}\right.$; Liu et al., 2014b). Such a low energy barrier explains the excellent absorption kinetics of the $\mathrm{Mg}-\mathrm{Pd}$ nanocomposite at low temperatures. As shown in the STEM images (Figure 2), $\mathrm{Pd}$ is homogeneously distributed on the surface or inside $\mathrm{Mg}$ particles, with the particle size ranging from 40 to $70 \mathrm{~nm}$. The reported theoretical calculations indicate that the Pd-dopant can provide a much lower activation barrier for both dissociation of molecular hydrogen and diffusion of atomic hydrogen on the $\mathrm{Mg}$ surface (Du et al., 2007). Pd in the form of small particles dispersed on the $\mathrm{Mg}$ particles can catalyze the dissociation of $\mathrm{H}_{2}$, and the adsorbed hydrogen atoms can be spilled over onto the surface of Mg nanoparticles, which is assigned as a "spillover" mechanism (Zaluskia et al., 1995). In addition, Pd may act as the "nanoportal" role, and hydride nucleation occurs only under Pd nanoparticles at lower hydrogenation temperature (Chung et al., 2015). Hence, it can be concluded that Pd homogeneously distributed on the surface or inside $\mathrm{Mg}$ particles can dissociate hydrogen and create a hydrogen diffusion pathway for the Mg nanoparticles.

\section{CONCLUSIONS}

In this work, a Mg-Pd nanocomposite was successfully coprecipitated from a homogeneous THF solution. STEM observations revealed that $\mathrm{Pd}$ was homogeneously distributed on the surface or inside $\mathrm{Mg}$ particles, with the particle size ranging from 40 to $70 \mathrm{~nm}$. The $\mathrm{Mg}-\mathrm{Pd}$ nanocomposite exhibits superior hydrogen storage properties. The hydrogen reaction enthalpies of the $\mathrm{Mg}-\mathrm{Pd}$ nanocomposite are slightly lower than that of pristine $\mathrm{MgH}_{2}$, indicating that the $\mathrm{Mg}-\mathrm{Pd}$ alloy plays an active role in the reversible metal hydride 
transformation and destabilizes the $\mathrm{MgH}_{2}$. For the hydrogenated $\mathrm{Mg}-\mathrm{Pd}$ nanocomposite at $150^{\circ} \mathrm{C}$, the onset dehydrogenation temperature is reduced to $216.8^{\circ} \mathrm{C}$, representing a $94.3^{\circ} \mathrm{C}$ reduction as compared with the pure $\mathrm{MgH}_{2}$ prepared through the same method. High-content $\gamma-\mathrm{MgH}_{2}$ along with $\mathrm{PH}_{0.706}$ is formed during the hydrogenation process, contributing to the enhancing desorption kinetics. The $\mathrm{Mg}-\mathrm{Pd}$ nanocomposite can take up $3.0 \mathrm{wt} \%$ hydrogen in $2 \mathrm{~h}$ at temperature low as $50^{\circ} \mathrm{C}$. During lower hydrogenation temperatures, $\mathrm{Pd}$ can dissociate hydrogen and create a hydrogen diffusion pathway for the Mg nanoparticles.

\section{DATA AVAILABILITY STATEMENT}

All datasets generated for this study are included in the article/supplementary material.

\section{REFERENCES}

Akyildiz, H., Ozenbas, M., and Ozturk, T. (2006). Hydrogen absorption in magnesium based crystalline thin films. Int. J. Hydr. Energy 31, 1379-1383. doi: 10.1016/j.ijhydene.2005.11.003

Callini, E., Pasquini, L., Piscopiello, E., Montone, A., Vittori Antisari, M., and Bonetti, E. (2009). Hydrogen sorption in Pd-decorated $\mathrm{Mg}-\mathrm{MgO}$ core-shell nanoparticles. Appl. Phys. Lett. 94:221905. doi: 10.1063/1.31 47205

Callini, E., Pasquini, L., Rude, L. H., Nielsen, T. K., Jensen, T. R., and Bonetti, E. (2010). Hydrogen storage and phase transformations in Mg-Pd nanoparticles. J. Appl. Phys. 108:073513. doi: 10.1063/1.3490206

Chung, C. J., Nivargi, C., and Clemens, B. (2015). Nanometer-scale hydrogen 'portals' for the control of magnesium hydride formation. Phys. Chem. Chem. Phys. 17, 28977-28984. doi: 10.1039/C5CP04515K

Crivello, J. C., Dam, B., Denys, R. V., Dornheim, M., Grant, D. M., Huot, J., et al. (2016). Review of magnesium hydride-based materials: development and optimisation. Appl. Phys. A 122:97. doi: 10.1007/s00339-016-9602-0

Cui, J., Liu, J., Wang, H., Ouyang, L., Sun, D., Zhu, M., et al. (2014). Mg-TM (TM: $\mathrm{Ti}, \mathrm{Nb}, \mathrm{V}, \mathrm{Co}, \mathrm{Mo}$ or $\mathrm{Ni}$ ) core-shell like nanostructures: synthesis, hydrogen storage performance and catalytic mechanism. J. Mater. Chem. A 2, 9645-9655. doi: 10.1039/C4TA00221K

Du, A. J., Smith, S. C., Yao, X. D., and Lu, G. Q. (2007). Hydrogen spillover mechanism on a Pd-doped $\mathrm{Mg}$ surface as revealed by ab initio density functional calculation. J. Am. Chem. Soc. 129, 10201-10204. doi: $10.1021 / \mathrm{ja} 0722776$

Ham, B., Junkaew, A., Arroyave, R., Chen, J., Wang, H., Wang, P., et al. (2013). Hydrogen sorption in orthorhombic Mg hydride at ultra-low temperature. Int. J. Hydr. Energy 38, 8328-8341. doi: 10.1016/j.ijhydene.2013.04.098

Higuchi, K., Yamamotob, K., Kajiokaa, H., Toiyamaa, K., Hondaa, M., Orimoc, S., et al. (2002). Remarkable hydrogen storage properties in three-layered $\mathrm{Pd} / \mathrm{Mg} / \mathrm{Pd}$ thin films. J. Alloys Comp. 330, 526-530. doi: $10.1016 /$ S0925-8388(01)01542-0

Huot, J., Yonkeu, A., and Dufour, J. (2009). Rietveld analysis of neutron powder diffraction of Mg6Pd alloy at various hydriding stages. J. Alloys Comp. 475, 168-172. doi: 10.1016/j.jallcom.2008.07.034

Jangir, M., Jain, A., Agarwal, S., Zhang, T., Kumar, S., Selvaraj, S., et al. (2018). The enhanced de/re-hydrogenation performance of $\mathrm{MgH} 2$ with $\mathrm{TiH} 2$ additive. Int. J. Energy Res. 42, 1139-1147. doi: 10.1002/er.3911

Jeon, K. J., Moon, H. R., Ruminski, A. M., Jiang, B., Kisielowski, C., Bardhan, R., et al. (2011). Air-stable magnesium nanocomposites provide rapid and highcapacity hydrogen storage without using heavy-metal catalysts. Nat. Mater. 10, 286-290. doi: $10.1038 /$ nmat2978

Kumar, S., Jain, A., Yamaguchi, S., Miyaoka, H., Ichikawa, T., Mukherjee, A., et al. (2017). Surface modification of $\mathrm{MgH} 2$ by $\mathrm{ZrCl} 4$ to tailor the

\section{AUTHOR CONTRIBUTIONS}

The manuscript was written through contributions of all authors. All authors have given approval to the final version of the manuscript.

\section{FUNDING}

This work was supported by the National Natural Science Foundation of China (51801100, 51771092, 21975125), Natural Science Foundation of the Jiangsu Higher Education Institutions of China (18KJB430014), Postgraduate Research \& Practice Innovation Program of Jiangsu Province (SJCX18_0341), Six Talent Peaks Project in Jiangsu Province (2018, XNY-020), and the Priority Academic Program Development (PAPD) of Jiangsu Higher Education Institutions.

reversible hydrogen storage performance. Int. J. Hydr. Energy 42, 6152-6159. doi: 10.1016/j.ijhydene.2017.01.193

Lin, H.-J., Matsuda, J., Li, H.-W., Zhu, M., and Akiba, E. (2015). Enhanced hydrogen desorption property of $\mathrm{MgH} 2$ with the addition of cerium fluorides. J. Alloys Comp. 645, S392-S396. doi: 10.1016/j.jallcom.2014. 12.102

Lin, H.-J., Tang, J.-J., Yu, Q., Wang, H., Ouyang, L.-Z., Zhao, Y.-J., et al. (2014). Symbiotic $\mathrm{CeH} 2.73 / \mathrm{CeO} 2$ catalyst: a novel hydrogen pump. Nano Energy 9, 80-87. doi: 10.1016/j.nanoen.2014.06.026

Liu, G., Wang, Y., Xu, C., Qiu, F., An, C., Li, L., et al. (2013). Excellent catalytic effects of highly crumpled graphene nanosheets on hydrogenation/dehydrogenation of magnesium hydride. Nanoscale 5, 1074-1081. doi: 10.1039/C2NR33347C

Liu, M., Xiao, X., Zhao, S., Chen, M., Mao, J., Luo, B., et al. (2019a). Facile synthesis of $\mathrm{Co} / \mathrm{Pd}$ supported by few-walled carbon nanotubes as an efficient bidirectional catalyst for improving the low temperature hydrogen storage properties of magnesium hydride. J. Mater. Chem. A 7, 5277-5287. doi: 10.1039/C8TA12431K

Liu, M., Xiao, X., Zhao, S., Saremi-Yarahmadi, S., Chen, M., Zheng, J., et al. (2019b). ZIF-67 derived Co@CNTs nanoparticles: remarkably improved hydrogen storage properties of $\mathrm{MgH} 2$ and synergetic catalysis mechanism. Int. J. Hydr. Energy 44, 1059-1069. doi: 10.1016/j.ijhydene.2018.11.078

Liu, Y., Zou, J., Zeng, X., and Ding, W. (2014a). A co-precipitated Mg$\mathrm{Ti}$ nano-composite with high capacity and rapid hydrogen absorption kinetics at room temperature. RSC $A d v .4,42764-42771$. doi: 10.1039/C4RA0 $5382 \mathrm{~F}$

Liu, Y., Zou, J., Zeng, X., and Ding, W. (2015). Study on hydrogen storage properties of $\mathrm{Mg}-\mathrm{X}(\mathrm{X}=\mathrm{Fe}, \mathrm{Co}, \mathrm{V})$ nano-composites co-precipitated from solution. RSC Adv. 5, 7687-7696. doi: 10.1039/C4RA12977F

Liu, Y., Zou, J., Zeng, X., Wu, X., Li, D., and Ding, W. (2014b). Hydrogen storage properties of a Mg-Ni nanocomposite coprecipitated from solution. J. Phys. Chem. C 118, 18401-18411. doi: 10.1021/jp504918x

Lu, J., Choi, Y. J., Fang, Z. Z., Sohn, H. Y., and Rönnebro, E. (2010). Hydrogenation of nanocrystalline $\mathrm{Mg}$ at room temperature in the presence of TiH2. J. Am. Chem. Soc. 132, 6616-6617. doi: 10.1021/ja910944w

Lukashev, R. V., Klyamkin, S. N., and Tarasov, B. P. (2006). Preparation and properties of hydrogen-storage composites in the $\mathrm{MgH} 2-\mathrm{C}$ system. Inorg. Mater. 42, 726-732. doi: 10.1134/S0020168506070077

Ma, L. P., Kang, X. D., Dai, H. B., Liang, Y., Fang, Z. Z., Wang, P. J., et al. (2009). Superior catalytic effect of $\mathrm{TiF} 3$ over $\mathrm{TiCl} 3$ in improving the hydrogen sorption kinetics of MgH2: catalytic role of fluorine anion. Acta Mater. 57, 2250-2258. doi: 10.1016/j.actamat.2009.01.025

Ma, T., Isobe, S., Wang, Y., Hashimoto, N., and Ohnuki, S. (2013). Nb-Gateway for hydrogen desorption in $\mathrm{Nb} 2 \mathrm{O} 5$ catalyzed $\mathrm{MgH} 2$ nanocomposite. J. Phys. Chem. C 117, 10302-10307. doi: 10.1021/jp4021883 
Norberg, N. S., Arthur, T. S., Fredrick, S. J., and Prieto, A. L. (2011). Size-dependent hydrogen storage properties of $\mathrm{Mg}$ nanocrystals prepared from solution. J. Am. Chem. Soc. 133, 10679-10681. doi: 10.1021/ja201791y

Pistidda, C., Bergemann, N., Wurr, J., Rzeszutek, A., Møller, K. T., Hansen, B. R. S., et al. (2014). Hydrogen storage systems from waste $\mathrm{Mg}$ alloys. J. Power Sources 270, 554-563. doi: 10.1016/j.jpowsour.2014. 07.129

Ponthieu, M., Cuevas, F., Fernández, J. F., Laversenne, L., Porcher, F., and Latroche, M. (2013). Structural properties and reversible deuterium loading of MgD2-TiD2 nanocomposites. J. Phys. Chem. C 117, 18851-18862. doi: $10.1021 / j p 405803 x$

Rather, S. U., Taimoor, A. A., Muhammad, A., Alhamed, Y. A., Zaman, S. F., and Ali, A. M. (2016). Kinetics of hydrogen adsorption on MgH2/CNT composite. Mater. Res. Bull. 77, 23-28. doi: 10.1016/j.materresbull.2016. 01.025

Rieke, R. D., and Hudnall, P. M. (1972). Activated metals. I. preparation of highly reactive magnesium metal. J. Am. Chem. Soc. 94, 7178-7179. doi: $10.1021 /$ ja00775a066

Rizo-Acosta, P., Cuevas, F., and Latroche, M. (2018). Optimization of TiH2 content for fast and efficient hydrogen cycling of $\mathrm{MgH} 2-\mathrm{TiH} 2$ nanocomposites. Int. J. Hydr. Energy 43, 16774-16781. doi: 10.1016/j.ijhydene.2018.04.169

Sander, J. M., Ismer, L., and Van De Walle, C. G. (2016). Point-defect kinetics in $\alpha$ - and $\gamma-\mathrm{MgH} 2$. Int. J. Hydr. Energy 41, 5688-5692. doi: 10.1016/j.ijhydene.2016.01.156

Schneemann, A., White, J. L., Kang, S., Jeong, S., Wan, L. F., Cho, E. S., et al. (2018). Nanostructured metal hydrides for hydrogen storage. Chem. Rev. 118, 10775-10839. doi: 10.1021/acs.chemrev.8b00313

Shena, C., and Aguey-Zinsou, K.-F. (2017). Can $\gamma-\mathrm{MgH} 2$ improve the hydrogen storage properties of magnesium? J. Mater. Chem. A 5, 8644-8652. doi: 10.1039/C7TA01724C

Singh, R. K., Sadhasivam, T., Sheeja, G. I., Singh, P., and Srivastava, O. N. (2013). Effect of different sized $\mathrm{CeO} 2$ nano particles on decomposition and hydrogen absorption kinetics of magnesium hydride. Int. J. Hydr. Energy 38, 6221-6225. doi: 10.1016/j.ijhydene.2012.12.060

Siviero, G., Bello, V., Mattei, G., Mazzoldi, P., Battaglin, G., Bazzanella, N., et al. (2009). Structural evolution of Pd-capped $\mathrm{Mg}$ thin films under $\mathrm{H} 2$ absorption and desorption cycles. Int. J. Hydr. Energy 34, 4817-4826. doi: 10.1016/j.ijhydene.2009.03.059

Sun, Y., Ma, T., and Aguey-Zinsou, K.-F. (2018). Magnesium supported on nickel nanobelts for hydrogen storage: coupling nanosizing and catalysis. ACS Appl. Nano Mater. 1, 1272-1279. doi: 10.1021/acsanm.8b00033

Tang, F., Parker, T., Li, H. F., Wang, G. C., and Lu, T. M. (2008). The Pd catalyst effect on low temperature hydrogen desorption from hydrided ultrathin $\mathrm{Mg}$ nanoblades. Nanotechnology 19:465706. doi: 10.1088/0957-4484/19/46/465706

Terent'ev, P. B., Gerasimov, E. G., Mushnikov, N. V., Uimin, M. A., Maikov, V. V., Gaviko, V. S., et al. (2015). Kinetics of hydrogen desorption from $\mathrm{MgH} 2$ and AlH3 hydrides. Phys. Metals Metallogr. 116, 1197-1202. doi: 10.1134/S0031918X15120121

Vajeeston, P., Ravindran, P., Hauback, B. C., Fjellvåg, H., Kjekshus, A., Furuseth, S., et al. (2006). Structural stability and pressure-induced phase transitions inMgH2. Phys. Rev. B 73:224102. doi: 10.1103/PhysRevB.73.2 24102

Varin, R. A., Czujko, T., and Wronski, Z. (2006). Particle size, grain size and gamma-MgH2 effects on the desorption properties of nanocrystalline commercial magnesium hydride processed by controlled mechanical milling. Nanotechnology 17, 3856-3865. doi: 10.1088/0957-4484/17/15/041

Wang, H., Hu, J., Han, F., Lu, Y., Liu, J., Ouyang, L., et al. (2015). Enhanced joint catalysis of $\mathrm{YH} 2 / \mathrm{Y} 2 \mathrm{O} 3$ on dehydrogenation of $\mathrm{MgH} 2$. J. Alloys Comp. 645, S209-S212. doi: 10.1016/j.jallcom.2015.01.057

Xiao, X., Liu, Z., Saremi-Yarahmadi, S., and Gregory, D. H. (2016). Facile preparation of $\beta / \gamma-\mathrm{MgH}(2)$ nanocomposites under mild conditions and pathways to rapid dehydrogenation. Phys. Chem. Chem. Phys. 18, 10492-10498. doi: 10.1039/C5CP07762A

Yao, X., Zhu, Z. H., Cheng, H. M., and Lu, G. Q. (2011). Hydrogen diffusion and effect of grain size on hydrogenation kinetics in magnesium hydrides. J. Mater. Res. 23, 336-340. doi: 10.1557/JMR.2008.0063

Yartys, V. A., Lototskyy, M. V., Akiba, E., Albert, R., Antonov, V. E., Ares, J. R., et al. (2019). Magnesium based materials for hydrogen based energy storage: past, present and future. Int. J. Hydr. Energy 44, 7809-7859. doi: 10.1016/j.ijhydene.2018.12.212

Zaluskia, L., Zaluskaa, A., Tessiera, P., Ström-Olsena, J. O., and Schulzb, R. (1995). Catalytic effect of Pd on hydrogen absorption in mechanically alloyed Mg2Ni, LaNi5 and FeTi. J. Alloys Comp. 217, 295-300. doi: 10.1016/0925-8388(94)01358-6

Zhang, X., Leng, Z., Gao, M., Hu, J., Du, F., Yao, J., et al. (2018). Enhanced hydrogen storage properties of $\mathrm{MgH} 2$ catalyzed with carbon-supported nanocrystalline TiO 2. J. Power Sources 398, 183-192. doi: 10.1016/j.jpowsour.2018.07.072

Zhang, Y., Zhuang, X., Zhu, Y., Wan, N., Li, L., and Dong, J. (2015). Synergistic effects of $\mathrm{TiH} 2$ and $\mathrm{Pd}$ on hydrogen desorption performances of $\mathrm{MgH} 2$. Int. J. Hydr. Energy 40, 16338-16346. doi: 10.1016/j.ijhydene.2015.09.029

Zhou, S., Ran, W., Yang, M., Wang, D., Chen, G., Zhang, Y., et al. (2013). Magnesium hydride of orthorhombic crystal from high-energy ball milling under hydrogen atmosphere. Adv. Mater. Res. 724-725, 1033-1036. doi: 10.4028/www.scientific.net/AMR.724-725.1033

Zhou, S., Zhang, Q., Chen, H., Zang, X., Zhou, X., Wang, R., et al. (2015). Crystalline structure, energy calculation and dehydriding thermodynamics of magnesium hydride from reactive milling. Int. J. Hydr. Energy 40, 11484-11490. doi: 10.1016/j.ijhydene.2015.02.059

Conflict of Interest: The authors declare that the research was conducted in the absence of any commercial or financial relationships that could be construed as a potential conflict of interest.

Copyright (C) $2020 \mathrm{Liu}, \mathrm{Zhu}, \mathrm{Liu}, \mathrm{Zhu}$, Zhang and Li. This is an open-access article distributed under the terms of the Creative Commons Attribution License (CC BY). The use, distribution or reproduction in other forums is permitted, provided the original author(s) and the copyright owner(s) are credited and that the original publication in this journal is cited, in accordance with accepted academic practice. No use, distribution or reproduction is permitted which does not comply with these terms. 